\title{
Prospective pharmacological methodology for establishing and evaluating anti-cancer drug resistant cell lines
}

Hoon $\mathrm{Yu}^{1}$, Dong-Jin Kim² ${ }^{2}$ Hye-Young $\mathrm{Choi}^{3}$, So Myoung Kim ${ }^{4,5}$, Md. Intazur Rahaman ${ }^{4,5}$, Young-Hoon Kim ${ }^{4,5^{*}}$ and So Won $\mathrm{Kim}^{4,5^{*}}$

\begin{abstract}
Background: Cell lines are often used to assess the resistance of anticancer drugs when in vivo analysis is not possible. However, the process for establishing anti-cancer drug resistance in cell cultures in vitro and the subsequent method of then evaluating resistance are not clearly established. Traditionally, the $I_{50}$ is the most commonly used indicator of resistance evaluation but it cannot represent the effectiveness of anti-cancer drugs in a clinical setting and lacks reliability because it is heavily affected by the cell doubling time. Hence, new indicators that can evaluate anti-cancer drug resistance are needed.

Methods: A novel resistance evaluation methodology was validated in this present study by establishing sunitinib resistance in renal cell carcinoma cells and assessing the cross-resistance of five different anti-cancer drugs.

Results: It was confirmed in this present study that the $I_{50}$ does not reflect the cell proliferation rates in a way that represents anti-cancer drug resistance. An alternative indicator that can also be clinically meaningful when using in vitro cell line systems is $\mathrm{Gl}_{100}$. Additionally, the $\mathrm{GR}_{100}$ allows different cell populations to be calibrated on the same basis when multiple experimental results are compared.

Conclusion: Since the $\mathrm{GR}_{100}$ has properties that indicate the efficiency of anti-cancer drugs, both the efficacy and $\mathrm{GR}_{100}$ of a particular anti-cancer drug can be used to effectively assess the resistance.
\end{abstract}

Keywords: Renal cell carcinoma, Sunitinib, Drug resistance, Cross-resistance, $I C_{50}, G_{100}$

\section{Background}

Human in vivo research systems would always yield the most accurate results when testing a clinical therapy, but are problematic to establish due to factors such as accessibility, risks, and ethical considerations, among others. Safer and simpler research systems that can somewhat reflect the clinical environment are therefore almost always used. It is vital in this circumstance that the

\footnotetext{
* Correspondence: kimyh@amc.seoul.kr; kswlab2015@gmail.com ${ }^{4}$ Department of Pharmacology, Asan Medical Center, University of Ulsan College of Medicine, 88, Olympic-ro 43-gil, Songpa-gu, Seoul, Republic of Korea

Full list of author information is available at the end of the article
}

research design should be as similar as possible to the clinical environment and that any in vitro data thereby obtained should be at a level that can be given serious consideration in a clinical setting. The cancer field is no exception and immortalized cell lines originally derived from human tissues are commonly used to conduct cancer research. Many studies have also established cells that are resistant to anti-cancer drugs using the $\mathrm{IC}_{50}$ as an indicator of resistance assessment without criticism [1-3]. It must be noted however that the $\mathrm{IC}_{50}$ measure has many weaknesses and is not actually a suitable indicator of the resistance of anti-cancer drugs. It thus remained necessary to establish a methodology for

(c) The Author(s). 2021 Open Access This article is licensed under a Creative Commons Attribution 4.0 International License, which permits use, sharing, adaptation, distribution and reproduction in any medium or format, as long as you give appropriate credit to the original author(s) and the source, provide a link to the Creative Commons licence, and indicate if changes were made. The images or other third party material in this article are included in the article's Creative Commons licence, unless indicated otherwise in a credit line to the material. If material is not included in the article's Creative Commons licence and your intended use is not permitted by statutory regulation or exceeds the permitted use, you will need to obtain permission directly from the copyright holder. To view a copy of this licence, visit http://creativecommons.org/licenses/by/4.0/. The Creative Commons Public Domain Dedication waiver (http://creativecommons.org/publicdomain/zero/1.0/) applies to the data made available in this article, unless otherwise stated in a credit line to the data. 
evaluating the resistance of anti-cancer drugs using in vitro cell systems and any such approach would need to be designed so that the findings could be applied to a clinical context.

The criteria for judging the effectiveness of anti-cancer drugs is a principal consideration in the design of any new methodology to measure resistance and can be ultimately summarized as whether a reduction in tumor size has been achieved [4-6]. Formal guidelines classify anticancer effects by considering the margin of error and specifying the degree of tumor size change [7]. In cell experiments, the tumor size change corresponds to a change in the number of cells and is usually shown on the $y$-axis of the graph as a dependent variable against the drug concentration. The $\mathrm{IC}_{50}$ has no clinical significance in this type of experiment because it indicates the concentration of a drug that has caused a $50 \%$ reduction in cell number compared to a control group that has not been treated (Fig. 1A). To have clinical meaning in terms of the anti-cancer effectiveness of a given drug, the number of cells should be equivalent or less than that prior to treatment ( $\mathrm{y}_{0}$ and less in Fig. 1A). This can be determined by evaluating the growth rate from the seeding cells, and utilizing the GI instead of the IC (Fig. 1A) [9]. Additionally, the IC can vary if cell doubling times are different. To address this, the GR system is a method of representing GI by calibrating the doubling time problem associated with the IC (Fig. 1B) $[8,10]$.

A new and effective anti-cancer drug resistance evaluation system is described and validated in this present study. In the analyses, the IC, GI, and GR indicators were compared by establishing cells that are resistant to sunitinib, one of the first choice drugs used to treat renal cell carcinoma (RCC). Only resistance assessment indicators before and after the establishment of resistant cells has been compared in prior studies whereas this present investigation observed changes in resistance assessment indicators over a long period during which resistance was established to verify the utility of resistance assessment indicators. After the establishment of sunitinib-resistant cells, their cross-resistance to five anti-cancer drugs was evaluated and these indicators were compared again.

\section{Methods}

\section{Cell culture conditions}

For this study, cells with a clear cytology, which includes the majority of RCCs, and short doubling times were preferred [8]. The SNU-228 and SNU-267 lines were thus chosen (00228 and 00267, Korean Cell Line Bank) and maintained in RPMI 1640 medium (LM011-03, Welgene) supplemented with $10 \%$ fetal bovine serum (FBS, 16000044; Gibco). The cells were incubated at $37^{\circ} \mathrm{C}$ in a $5 \% \mathrm{CO}_{2}$ humidified incubator. To establish sunitinib resistance, the methods described by Martina et al. were referred to [3]. Briefly, the cells were exposed to sunitinib on a six-week cycle. Reflecting the clinical administration of sunitinib, the drugs were administered for 4 weeks and then withdrawn for 2 weeks. After the cells were exposed to the test drug for 4 weeks, the concentration of the drug was halved every $48 \mathrm{~h}$ with consideration of the 40 to $60 \mathrm{~h}$ half-life in the body, to simulate the clinical two-week withdrawal period [11]. The drug concentrations used are described in Supplementary Table 1 . The cells were continuously exposed to culture medium containing the drug, even during subculture, except when viability measurements were conducted in 96-well plates.
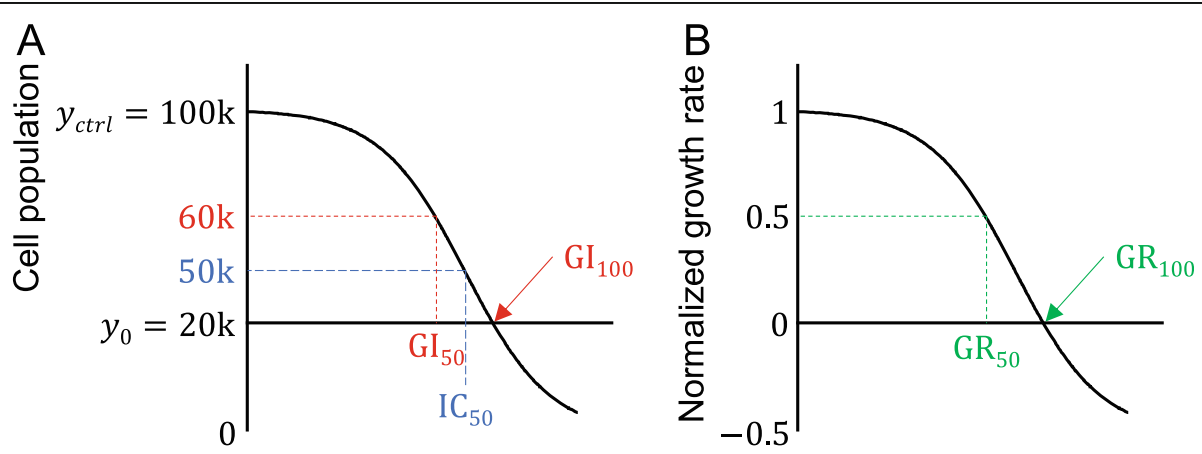

Fig. 1 Candidate indicators of anti-cancer drug resistance in cell lines. A The graph indicates anti-cancer drug treatment of cells, and measures the number of living cells, over a certain period of time. The $y$-axis refers to the number of cells and the $x$-axis refers to the concentration of anticancer drugs. $y_{0}$ is the number of cells just before exposure to the anti-cancer drug, and $y_{\text {ctrl }}$ is the number of cells after a certain period of time in the control group of cells that are not treated. $I C_{50}$ refers to the drug concentration when the number of cells is $50 \%$ of that of the $y_{c t r l}$ regardless of the value of $y_{0}$. Gl refers to the inhibition of cell proliferation so that the $\left(y_{c t r l}-y_{0}\right)$ value becomes a $100 \%$ cell proliferation rate. Gl 50 is the concentration of the drug at which cell proliferation is reduced by $50 \%$, i.e. the concentration at which the number of cells is $\left(y_{0}+\frac{y_{c t r l}-y_{0}}{2}\right)$, and $\mathrm{Gl}_{100}$ is the concentration at $y_{0}$. $\mathbf{B}$ In graph A, replacing the cell population with a normalized growth rate takes into account the cell doubling time, resulting in a $y$-axis value of between -1 and 1 . At this point, the drug concentration corresponding to the $y$-axis value of 0.5 is the $\mathrm{GR}_{50}$, and the concentration corresponding to 0 is the $\mathrm{GR}_{100}$. This figure is an adaptation of a figure published previously by Brooks et al. [8] 


\section{Chemicals}

The drugs used in this study were as follows: sunitinib (SYN-1086-M001, Adipogen Life Sciences); axitinib (SYN-1014-M010, Adipogen); cabozantinib (S1119, Selleckchem); pazopanib (CDS023580-25MG, Sigma Aldrich, St. Louis, MO); sorafenib (AG-CR1-0025-M005, Adipogen); everolimus (ab142151, Abcam); and temsirolimus (PZ0020-5MG, Sigma).

\section{Cell viability measurement}

Live cells were quantitatively measured using an EZCYTOX cell viability, proliferation, \& cytotoxicity assay kit (EZ-3000, DoGenBio) in accordance with the manufacturer's instructions. Briefly, SNU-228 and SNU-267 cells were seeded in a 96-well plate at a density of 1000 and 2000 cells, and in $100 \mu \mathrm{l}$ media per well, respectively. At $24 \mathrm{~h}$ after cell seeding, the tested drugs were added over a concentration gradient. EZ-CYTOX solution $(10 \mu \mathrm{l})$ was added to the cells at $72 \mathrm{~h}$ after the drug exposure. After $1 \mathrm{~h}$ of incubation at room temperature, the plates were gently shaken to mix the contents for $30 \mathrm{~s}$, and cell viability was estimated by the absorbance readings at a $450 \mathrm{~nm}$ wavelength, measured using a microplate reader.

\section{Usage indicators for evaluating the effects of the drugs on cell survival}

The $\mathrm{IC}_{50}, \mathrm{GI}_{50}, \mathrm{GI}_{100}, \mathrm{GR}_{50}$, and $\mathrm{GR}_{100}$ were calculated in the experiments, all among the known indicators of drug efficacy (Fig. 1) and that are defined as follows [8]. The $\mathrm{IC}_{50}$ denotes the concentration of a drug that causes a reduction in the cell population to half the number at zero time (i.e. the point immediately before the drug is added). The $\mathrm{GI}_{50}$ is the drug concentration that produces a reduced cell growth from seeding to $50 \%$ of the maximum, and the $\mathrm{GI}_{100}$ reflects the drug concentration at which the number of seeding states is maintained. When the $y$-axis is normalized by taking into account the cell doubling time, the drug concentration at the normalized counts of 0.5 and 0 is defined as the $G_{50}$ and $G_{100}$, respectively. In this present study, the $G_{50}$ and $\mathrm{GR}_{100}$ values were calculated using the previously described fixed-interval formula as follows [10]:

$$
G R(c)=2^{\frac{\log _{2}\left(x_{(c)} / x_{0}\right)}{\log _{2}\left(x_{c t r l} / x_{0}\right)}}-1
$$

\section{Statistical analysis}

Trends with regards to increasing or decreasing indicators related to cell growth or drug reactions were analyzed by linear regression, and 95\% confidence intervals were calculated. Statistical significance was determined by a $p$-value of 0.05 or less.

\section{Results}

\section{Process for establishing resistant cells}

In order to properly measure cell viability following exposure to an anti-cancer drug, the number of cells seeded onto 96-well plates needs to be accurately determined in advance. This is to ensure that cells are not affected by effects other the drug exposure when proliferating. SNU-228 cells were seeded at a density of $500-10,000 /$ well and their viability was measured every $24 \mathrm{~h}$. For the 500 and 1000 cells/well densities, the slope of the graph continues to increase until $72 \mathrm{~h}$. However, in terms of the number of cells, the slope of the graph decreased from $48 \mathrm{~h}$. This indicated that the proliferation had slowed from the $48 \mathrm{~h}$ timepoint due to cell saturation. At a 2000 cells/well density for the SNU-267 line, there were no affects of cell saturation on the increases in proliferation. Hence, the experiments using SNU-228 cells were conducted at 1000/well and using SNU-267 at 2000/well in a 96-well plate to eliminate any confounding impacts of cell saturation (Fig. 2A, B). When growing cells in a larger plate or flask, the area ratio in relation to the 96-well plate was calculated and the cells were seeded accordingly.

Once the appropriate number of cells to seed has been determined, the concentration of the drug to add to culture medium must be determined to establish resistance. The concentrations used in clinical settings are preferable in this regard, and the drug dosage and blood concentration are the available parameters. The blood concentration is not particularly helpful however because it differs from the target organ concentration. The concentration in the present experiments was thus determined based on the cell responses to the drug. However, treatments with drugs at concentrations that can reduce the number of cells targeted in a clinical setting ( $y_{0}$ or higher) is not easy to maintain for long periods of time in a laboratory. In this current study, the concentrations that reduced cell growth by $50 \%$ were used (i.e. the $\mathrm{GI}_{50}$ ). The $\mathrm{GI}_{50}$ value was measured at $2.97 \mu \mathrm{M}$ for SNU-228 cells and 5.67 $\mu \mathrm{M}$ for SNU267 cells, and it was finally decided to expose these cell types to $3 \mu \mathrm{M}$ and $5.5 \mu \mathrm{M}$ doses, respectively, for convenience (Fig. 2C, D).

\section{Process for establishing sunitinib-resistant cells}

To establish drug resistance, the SNU-228 cells were exposed to $3 \mu \mathrm{M}$ sunitinib for a total of 831 days. Sunitinib is clinically used over a 6 week cycle (a two-week break after a four-week treatment), and the cell cultures were treated accordingly and the drug half life was considered (Supplementary Table 1). From day 568 after the initial exposure of this cell line, a group of cells that had been drugremoved was added to determine whether the onset of resistance was reversible. The SNU-267 cells were exposed to sunitinib for a total of 957 days. Sunitinib exposure was 

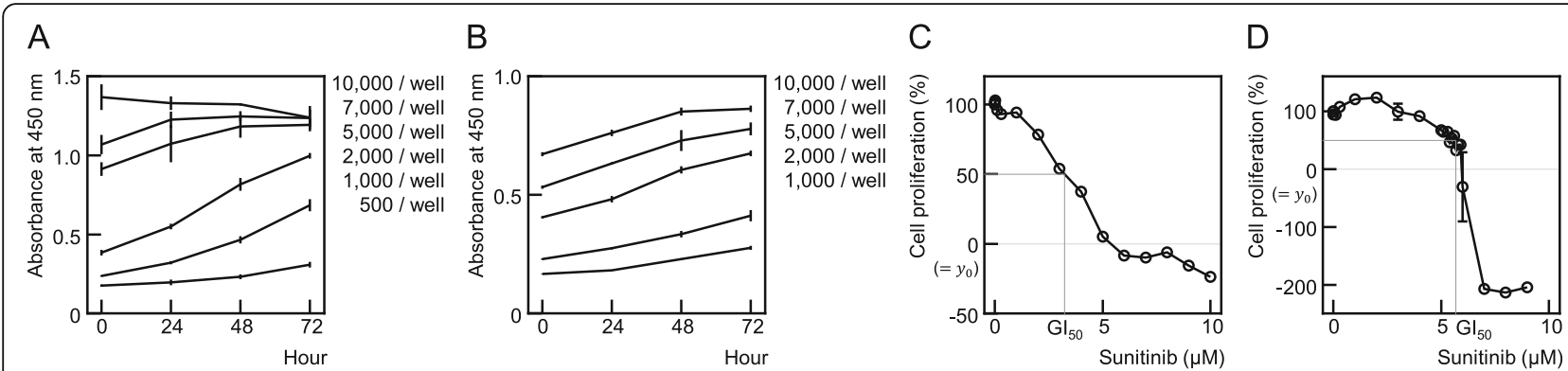

Fig. 2 Determining the appropriate number of cells and the sunitinib concentration required to generate sunitinib-resistance in SNU-228 and SNU-267 cells. Cell proliferation was measured for $72 \mathrm{~h}$ after seeding the cells at 500, 1000, 2000, 5000, 7000, and 10,000 cells/well in 96-well plates; A SNU-228 and B SNU-267 cells. The $y$-axis is the absorbance measured at $450 \mathrm{~nm}$ (A and B). The population of SNU-228 cells was measured after 1000 cells/well were seeded in 96-well plates and then exposed to a concentration gradient of sunitinib for $72 \mathrm{~h} \mathrm{(C)}$. SNU-267 cells were tested in the same way after 2000 cells/well were seeded (D). The $\mathrm{Gl} \mathrm{I}_{50}$ values were then calculated. This experiment was conducted three times independently

initiated at a dose of $5.5 \mu \mathrm{M}$, and the concentration was increased to $7 \mu \mathrm{M}$ on the day 568. A group of drugremoved cells was added on day 785 (Fig. 3).

Trends in the occurrence of resistance and comparison of resistance indicator candidates after exposure to sunitinib To confirm the establishment of resistance in the two RCC cell lines used in this study, their cellular appearance was first observed. It was possible to confirm that morphological changes had occurred in the cells after the sunitinib treatment regimen was fully completed. The control cells showed an elongated shape for both the SNU-228 and SNU-267 lines, whereas the sunitinib-treated cells were much shorter. Even in the treated cells that had been sunitinib free for 3 months since resistance was established, the control cell shape was not restored (Fig. 4).

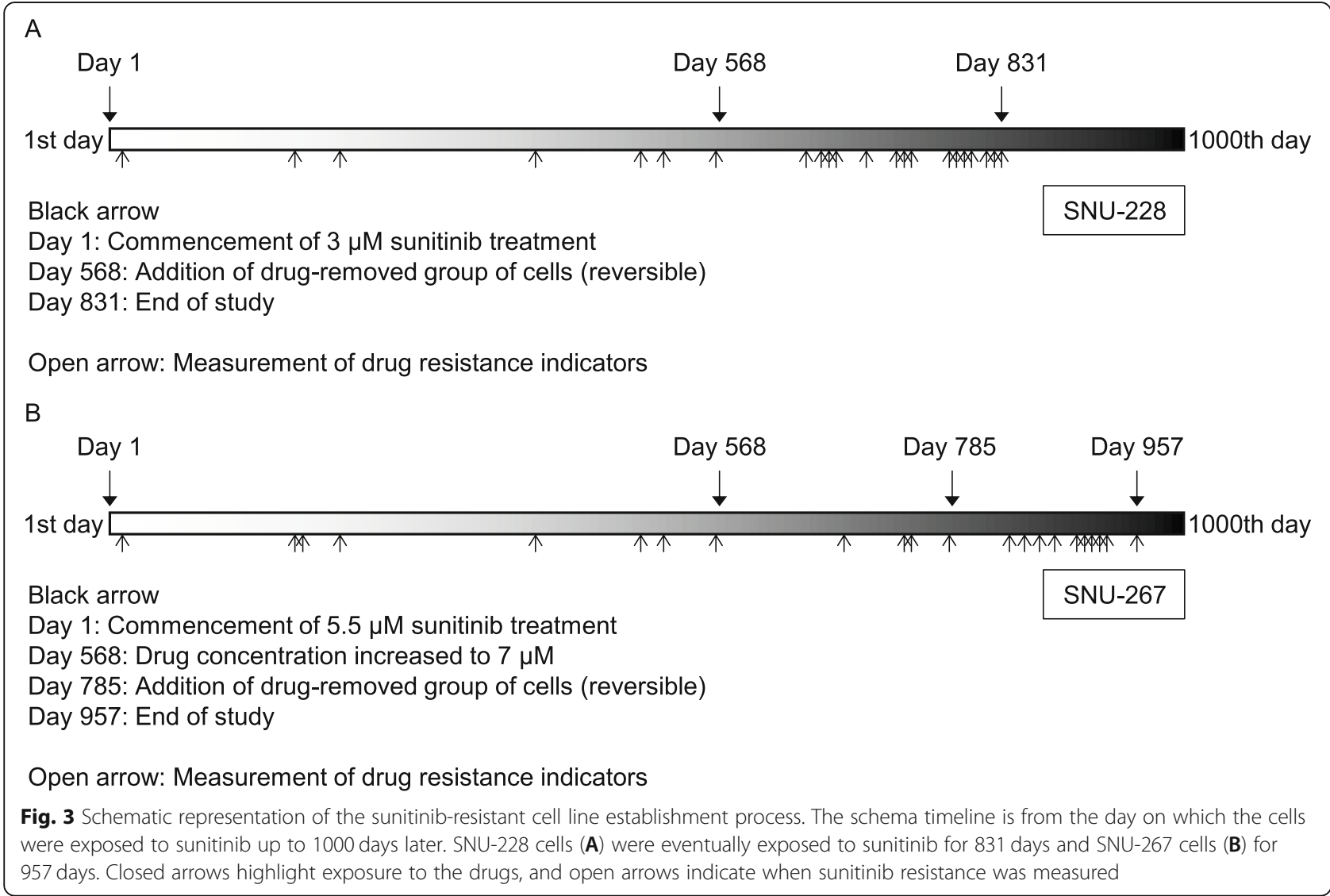




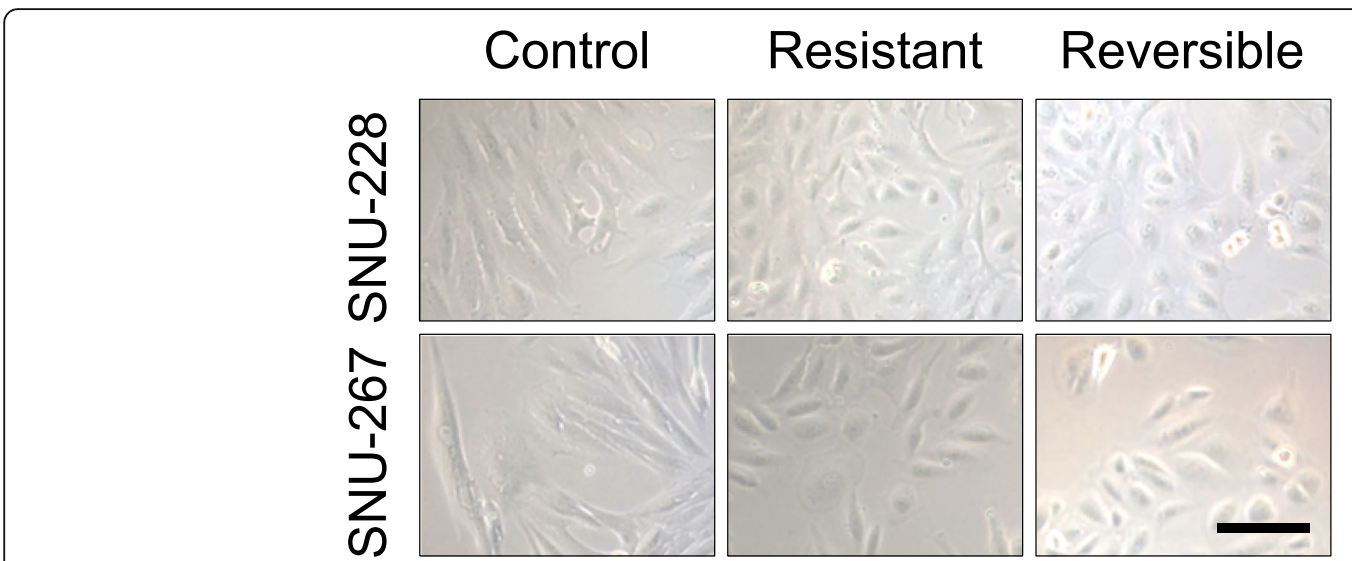

Fig. 4 Changes in the SNU-228 and SNU-267 morphologies due to sunitinib exposure. The shapes of the cells were monitored in the control, sunitinib-resistant, and sunitinib removal cells. Scale bar, $100 \mu \mathrm{m}$

After exposure of the two RCC cell lines to sunitinib, as shown in Fig. 3, cell viability were measured and resistance indicators were evaluated. The establishment of resistance was confirmed by linear regression indicating a straight line of resistance indicators over time. The results of the linear regression analysis for all resistance indicators are presented in Table 1 for SNU-228 cells and in Table 2 for SNU-267 cells.

The factor that was found to best represent resistance to anti-cancer drugs was changes in cell proliferation. The growth rate of the control SNU-228 cells was measured for $72 \mathrm{~h}$ and listed according to date. The growth rate trend of the control cells showed no statistically significant increase $(p=$ 0.2863 ) whereas the sunitinib-exposed cells had a statistically significantly increased rate $(p<0.0001$, Fig. 5A). Similar results were obtained for the SNU267 cells. Again, the cell growth rate of the control group cells was not statistically different $(p=0.6668)$ whereas that of the sunitinib-treated cells increased $(p=0.0007$, Fig. 6A).

The trends in terms of $\mathrm{IC}_{50}$ values, which are calculated based on the total number of cells and are the most utilized measure of drug activity, were next analyzed. The SNU-228 cells showed no statistically significant pattern of increase in this value in either the control or sunitinib-treated cells $(p=0.3957$ and 0.3077 , Fig. 5B). In the SNU-267 cells also, there was no pattern of increase in the $\mathrm{IC}_{50}$ values in either the control cells $(p=0.4847)$ or sunitinib-treated cells $(p=0.7798$, Fig. $6 \mathrm{~B})$. There were some instances at particular timepoints in which the $\mathrm{IC}_{50}$ of the sunitinib-treated cells was higher than that of the control cells (i.e. 1.42-fold higher at 684 days after sunitinib treatment in the SNU-267 cells). However, the analyses over the entire study period indicated no specific increases compared to the control cells. Hence, the $\mathrm{IC}_{50}$ values did not reflect the process of establishing resistance.

Table 1 Simple linear regression analysis of resistance indicator candidates using sunitinib-treated SNU-228 cells

\begin{tabular}{lllll}
\hline & & Equation & 95\% confidence interval of slope & $\boldsymbol{p}$ value \\
\hline Growth rate & Control cells & $y=0.04988 x+134.9$ & -0.04465 to 0.1444 & 0.2863 \\
& Resistant cells & $y=0.2151 x+66.28$ & 0.1348 to 0.2954 & $<0.0001$ \\
$I_{50}$ & Control & $y=0.002971 x+5.56$ & -0.004794 to 0.01074 & 0.3957 \\
& Resistant cells & $y=0.00237 x+6.11$ & -0.003783 to 0.008524 & 0.3077 \\
$\left.G\right|_{50}$ & Control & $y=0.000812 x+2.484$ & -0.002979 to 0.004603 & 0.6491 \\
& Resistant cells & $y=0.00326 x+2.838$ & -0.00002263 to 0.006543 & 0.0513 \\
$\left.G\right|_{100}$ & Control & $y=0.006882 x+4.776$ & -0.0003099 to 0.01407 & 0.0588 \\
& Resistant cells & $y=0.04409 x-7.048$ & 0.025 to 0.06317 & 0.0019 \\
$G R_{50}$ & Control & $y=0.001119 x+2.339$ & -0.002605 to 0.004843 & 0.5251 \\
$G_{100}$ & Resistant cells & $y=0.003732 x+2.54$ & 0.0005129 to 0.00695 & 0.0269 \\
& Control & $y=0.006869 x+4.79$ & -0.0003287 to 0.01407 & 0.0594 \\
\hline
\end{tabular}


Table 2 Simple linear regression analysis of resistance indicator candidates using sunitinib-treated SNU-267 cells

\begin{tabular}{|c|c|c|c|c|}
\hline & & Equation & $95 \%$ confidence interval of slope & $p$ value \\
\hline \multirow[t]{2}{*}{ Growth rate } & Control & $y=0.04181 x+244.4$ & -0.1577 to 0.2414 & 0.6668 \\
\hline & Resistant cells & $y=0.4506 x+107.4$ & 0.2190 to 0.6821 & 0.0007 \\
\hline \multirow[t]{2}{*}{$\mathrm{I}_{50}$} & Control & $y=0.0006978 x+5.224$ & -0.001398 to 0.002793 & 0.4847 \\
\hline & Resistant cells & $y=0.0003528 x+6.639$ & -0.002357 to 0.003063 & 0.7798 \\
\hline \multirow[t]{2}{*}{$\mathrm{Gl}_{50}$} & Control & $y=0.0004711 x+4.34$ & -0.001095 to 0.002037 & 0.5293 \\
\hline & Resistant cells & $y=0.001636 x+4.439$ & -0.0005583 to 0.00383 & 0.1303 \\
\hline \multirow[t]{2}{*}{$\mathrm{Gl}_{100}$} & Control & $y=-0.0001539 x+6.351$ & -0.00131 to 0.001002 & 0.7805 \\
\hline & Resistant cells & $y=0.007164 x+4.328$ & 0.004733 to 0.009596 & $<0.0001$ \\
\hline \multirow[t]{2}{*}{$\mathrm{GR}_{50}$} & Control & $y=0.000252 x+4.646$ & -0.0008375 to 0.001342 & 0.6275 \\
\hline & Resistant cells & $y=0.002473 x+4.427$ & 0.0004343 to 0.004512 & 0.0215 \\
\hline \multirow[t]{2}{*}{$\mathrm{GR}_{100}$} & Control & $y=-0.0003388 x+6.453$ & -0.001525 to 0.000847 & 0.5516 \\
\hline & Resistant cells & $y=0.007258 x+4.248$ & 0.004843 to 0.009674 & $<0.0001$ \\
\hline
\end{tabular}

The $\mathrm{GI}_{50}$ is the second most commonly used parameter after the $\mathrm{IC}_{50}$ for assessing the effectiveness of an anti-cancer drug, and is calculated on a growth rate basis, not on the highest number of cells. The $\mathrm{GI}_{50}$ values in sunitinib-treated SNU-228 cells seemed to differ from the control cells over time, but this was not statistically significant $(p=0.6491$ for control and $p=$ 0.0513 for sunitinib treated cells, Fig. 5C). Similarly, there was no statistical increase in the $\mathrm{GI}_{50}$ in either the control or sunitinib-treated SNU-267 cells $(p=0.5293$ and 0.1303, Fig. 6C).

The $\mathrm{GI}_{100}$ parameter is a concept that adds clinical significance to the concentration at which cell growth is at least $100 \%$ inhibited. There was no statistical increase in the $\mathrm{GI}_{100}$ values of the SNU-228 control cells $(p=$ 0.0588 ), but this measurement was increased in the sunitinib-treated cells $(p=0.0019$, Fig. 5D). A similar pattern appeared in SNU-267 cells, i.e. there was no increase in the SNU-267 control cells $(p=0.7805)$ but a significant increase was found in the sunitinib-treated cells $(p<0.0001$, Fig. 6D). In addition, and unlike the $\mathrm{GI}_{50}$, the trend in relation to the $\mathrm{GI}_{100}$ values showed statistical differences between the control cells and sunitinib-treated cells.

The $\mathrm{GR}_{50}$ results in this study, a measure which was developed previously by Hafner and colleagues that takes account of the cell doubling time as an indicator of an anti-cancer drug's effectiveness, were confirmed. SNU228 control cells showed no trend in terms of an increase $(p=0.5251)$ whereas the sunitinib-treated cells showed an increased pattern for the $\mathrm{GR}_{50}$ values $(p=$ 0.0269 , Fig. 5E). SNU-267 control cells also showed no increase $(p=0.6275)$ whereas sunitinib-treated cells showed an increasing pattern in relation to the $\mathrm{GR}_{50}$ $(p=0.0215$, Fig. 6E).

Lastly, the $\mathrm{GR}_{100}$ value of the SNU-228 control cells showed no statistically significant increase $(p=0.0594)$, and the progression of the $\mathrm{GR}_{100}$ values in the cells continuously exposed to sunitinib were statistically increased $(p=0.0019$, Fig. $5 \mathrm{~F})$. The $\mathrm{GR}_{100}$ values of the control SNU-267 cells also showed no increase $(p=$ 0.5516 ), whereas the $\mathrm{GR}_{100}$ of the cells exposed to sunitinib was increased significantly ( $p<0.0001$, Fig. 6 F).

Based on the current observations of changes in the resistance indicators during sunitinib treatment of SNU228 and SNU-267 cells, the $\mathrm{IC}_{50}$ and $\mathrm{GI}_{50}$ values were observed not to reflect the resistance establishment process, while the $\mathrm{GI}_{100}, \mathrm{GR}_{50}$ and $\mathrm{GR}_{100}$ values continued to increase.

The advantages and disadvantages of different resistance assessment indicator candidates

Different resistance evaluation indicators were compared in SNU-228 cells treated with axitinib, which was one of the cross-resistance evaluations conducted in this study. When a horizontal line was drawn along the y-axis of the graph pointing to the $\mathrm{IC}_{50}\left(y_{I C 50}\right)$, it was observed that the sunitinib-resistant and reversible cells reached an $\mathrm{IC}_{50}$ at a certain concentration, but that the control cells did not even if the concentration of axitinib was increased. In this case, if cross-resistance was assessed using the $\mathrm{IC}_{50}$ levels, the sunitinib-resistant cells $\left(\mathrm{IC}_{50}=\right.$ $6.33 \mu \mathrm{M})$ were found to more sensitive to axitinib than the control cells $\left(\mathrm{IC}_{50}>20 \mu \mathrm{M}\right)$. Reversible cells $\left(\mathrm{IC}_{50}=\right.$ $15.67 \mu \mathrm{M})$ were also found to be more than twice as resistant to axitinib than sunitinib-resistant cells (Fig. 7A). This can happen because the doubling time between cell types varies.

If a horizontal line is drawn with the number of seeded cells on the y-axis $\left(y_{0}\right)$, it can be seen that the crossresistance pattern is different from the $\mathrm{IC}_{50}$. The concentration of axitinib, which was the $\mathrm{x}$-axis corresponding to the intersection of the horizontal line and the graph, indicates the $\mathrm{GI}_{100}$ value. Axitinib cross- 


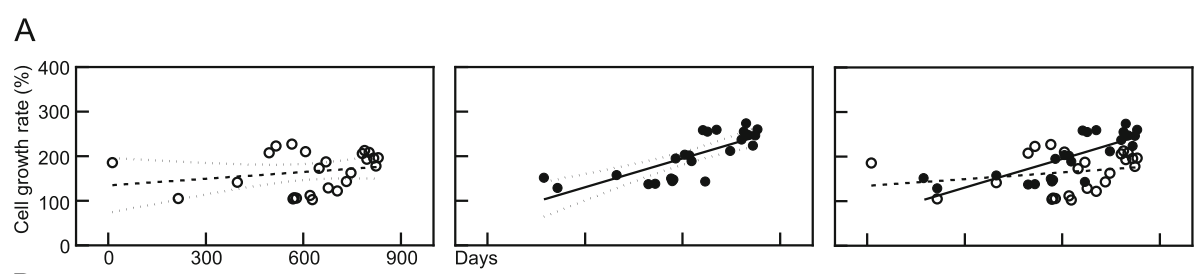

B
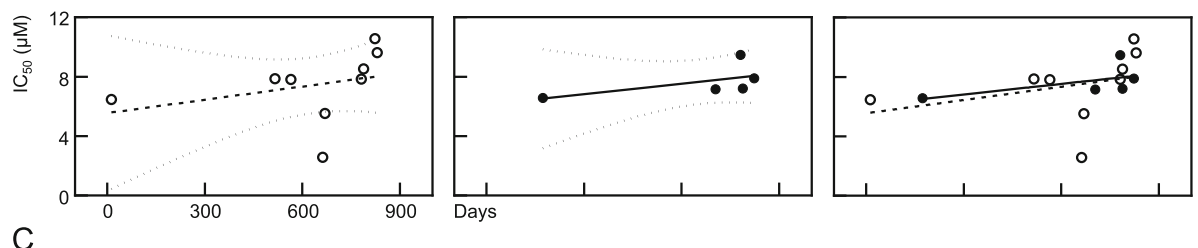

C
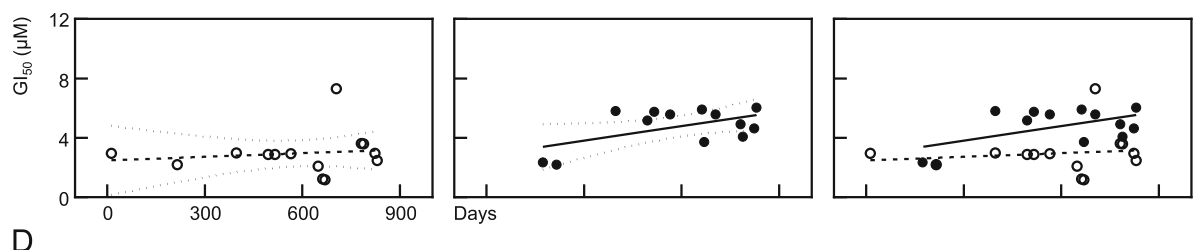

D
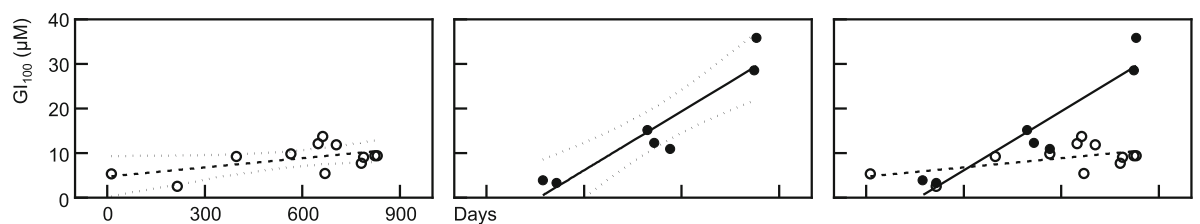

$\mathrm{E}$
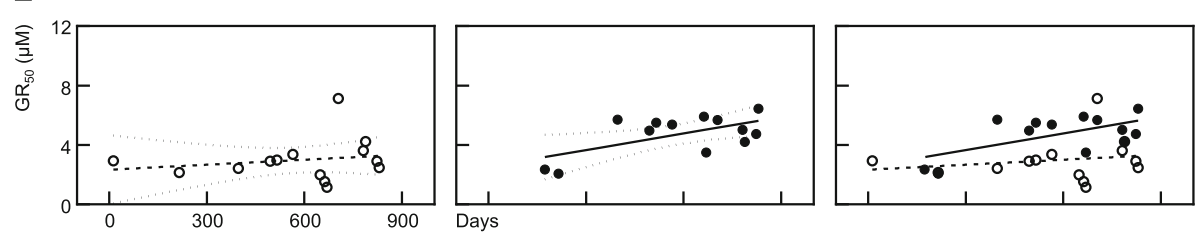

$\mathrm{F}$
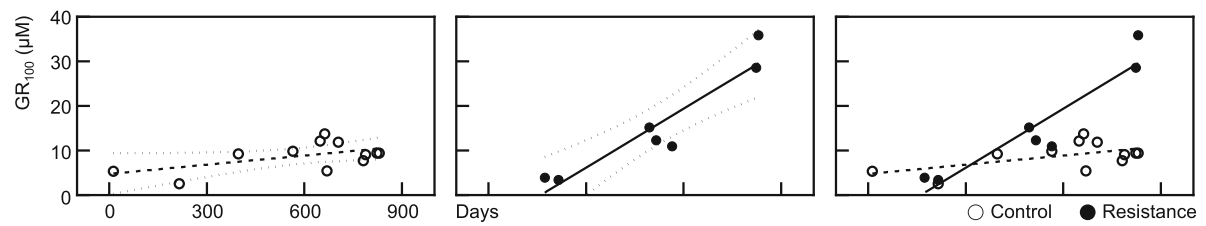

Fig. 5 Trends for cell growth and resistance indicator candidates in SNU-228 cells in accordance with the duration of exposure to sunitinib. The cell growth rate and resistance indicator candidates in SNU-228 cells measured on the dates indicated by the open arrows in Fig. 3 are displayed graphically by date. Data from the control groups not exposed to drugs are shown in the left column, the resistant groups exposed to sunitinib are shown in the middle column, and the two groups combined are shown in the right column. The results of simple linear regression analysis are shown in a straight line and the 95\% confidence interval is also shown in the left and middle columns

resistance levels were measured at $9.48 \mu \mathrm{M}$ in control cells, $23.19 \mu \mathrm{M}(4.21$-fold higher $)$ in sunitinib-resistant cells, and $17.38 \mu \mathrm{M}$ (3.15-fold higher) in reversible cells. The $\mathrm{IC}_{50}$ was found not only to be unstable in terms the value itself but also lacking in any clinical relevance, whereas the $\mathrm{GI}_{100}$ values was observed to be stable and to denote the clinically ineffective concentration of an anticancer drug.

When the y-axis indicates the cell population, it is difficult to make a comparison at a glance because the baselines for both the $\mathrm{IC}_{50}$ and GI_s on different graphs are different. By changing the $y$-axis to the cell proliferation rate (\%), the GI_values can be compared on the same basis. Moreover, changing the $y$-axis to the normalized growth rate, which takes into account the doubling time of the cell, allows for a more accurate assessment of drug resistance. In this instance, the $\mathrm{x}$-axis corresponding to 0.5 of the $\mathrm{y}$-axis indicates the $\mathrm{GR}_{50}$, and the $\mathrm{x}$-axis corresponding to 0 is the $\mathrm{GR}_{100}$. According to Hafner et al., the $\mathrm{GR}_{50}$ can express the cell death effects of the drug, but if the $\mathrm{GR}_{100}$ is used, it will 


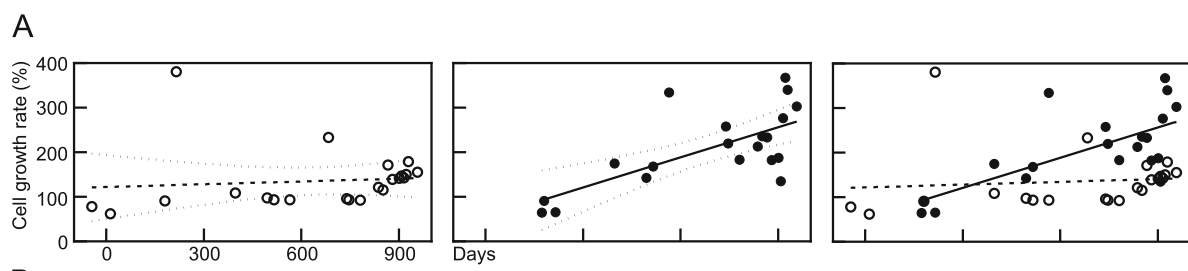

$\mathrm{B}$
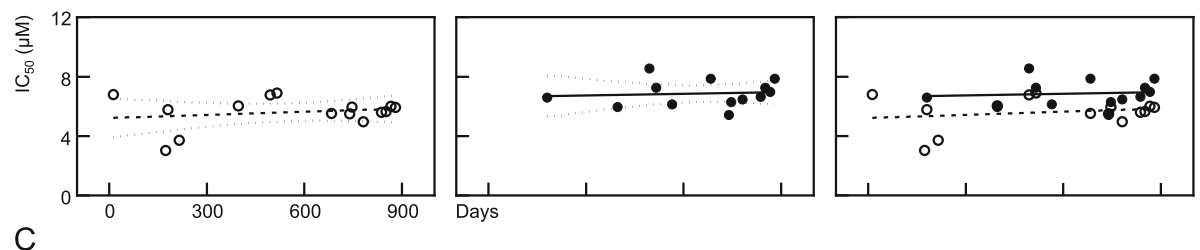

C
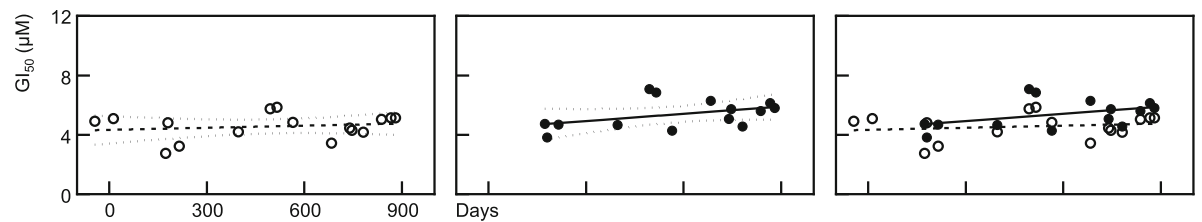

D
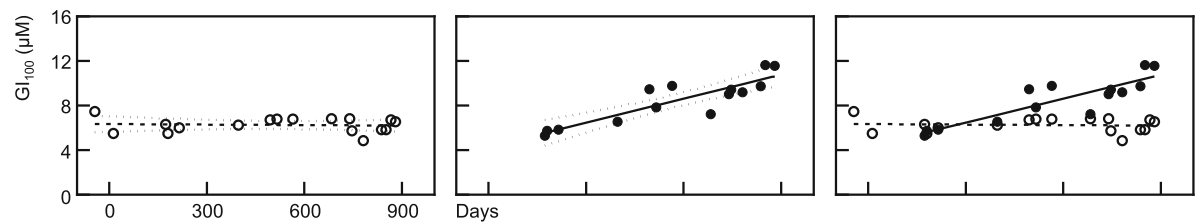

$\mathrm{E}$
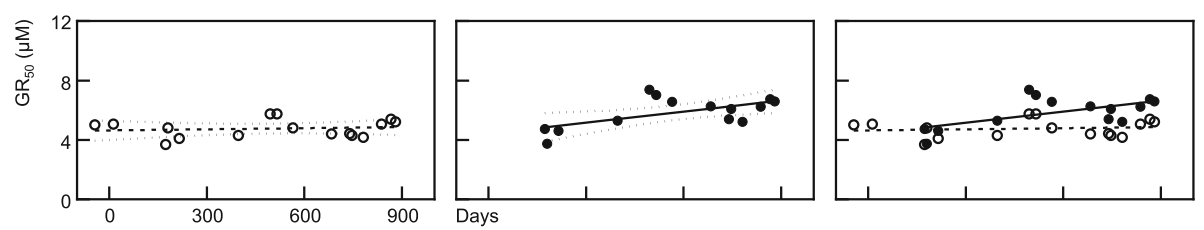

$\mathrm{F}$
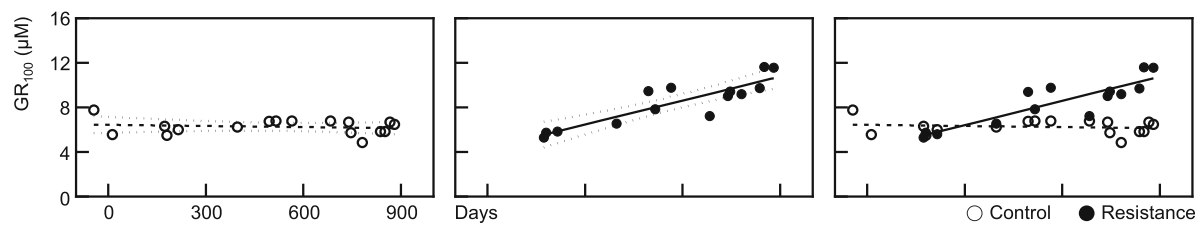

Fig. 6 Trends for cell growth and resistance indicator candidates in SNU-267 cells in accordance with the duration of exposure to sunitinib. Identical experiments to those described in Fig. 5 were conducted in SNU-267 cells

have clinical meaning, thus making it a better indicator of resistance. In evaluating the cross-resistance of axitinib with the $\mathrm{GR}_{100}$ in the present study, a value of $5.58 \mu \mathrm{M}$ was calculated in control cells, $19.37 \mu \mathrm{M}$ (3.47-fold higher) in sunitinib-resistant cells, and $17.91 \mu \mathrm{M}$ (3.21-fold higher) in reversible cells.

Two factors to consider when evaluating the resistance of anti-cancer drugs

The resistance assessment indicators discussed thus far in this study cannot alone represent all of the features of resistance. The $\mathrm{GR}_{100}$ (or at least the $\mathrm{GI}_{100}$ ), which is claimed to be useful based on the findings of this study, was used as an indicator of drug efficiency because this is a minimum requirement for assessing anti-cancer drug effectiveness. Figure 8 shows the cross-resistance of five anti-cancer drugs in sunitinib-resistant cells. The best example of this from the present analyses was that in SNU-228 cells, the $\mathrm{GR}_{100}$ for everolimus was almost identical (i.e. within a $10 \%$ range) between the control cells and sunitinib-resistant cells. However, as the concentration of everolimus increased, the rate of proliferation of these two cell types changed. At the highest concentration, the cell proliferation rate forms a plateau, which is the best effect of everolimus (efficacy). At this highest concentration, the control cell proliferation 
A
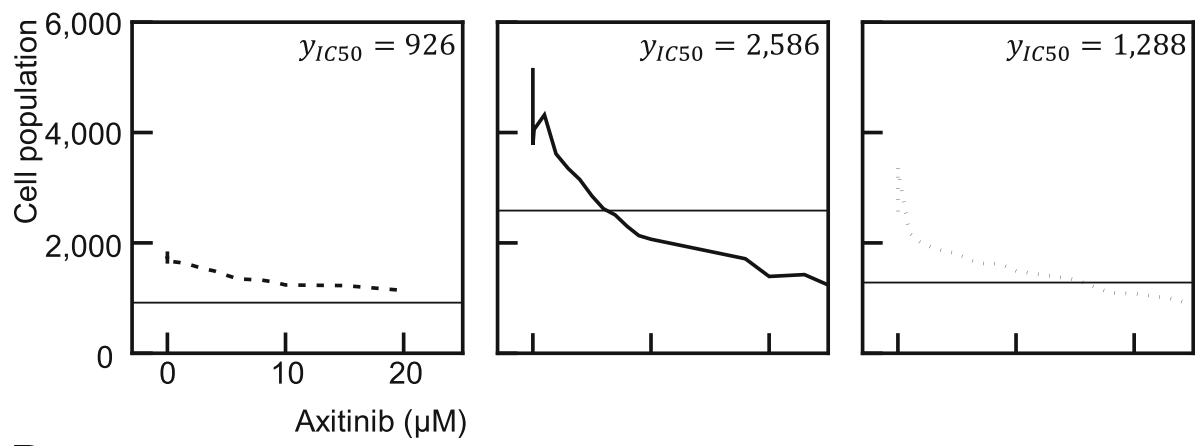

B
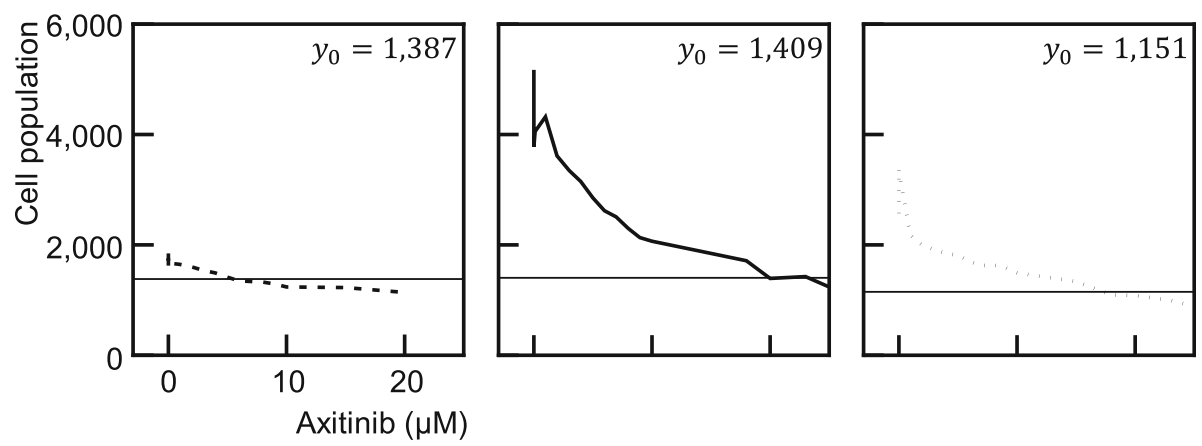

C
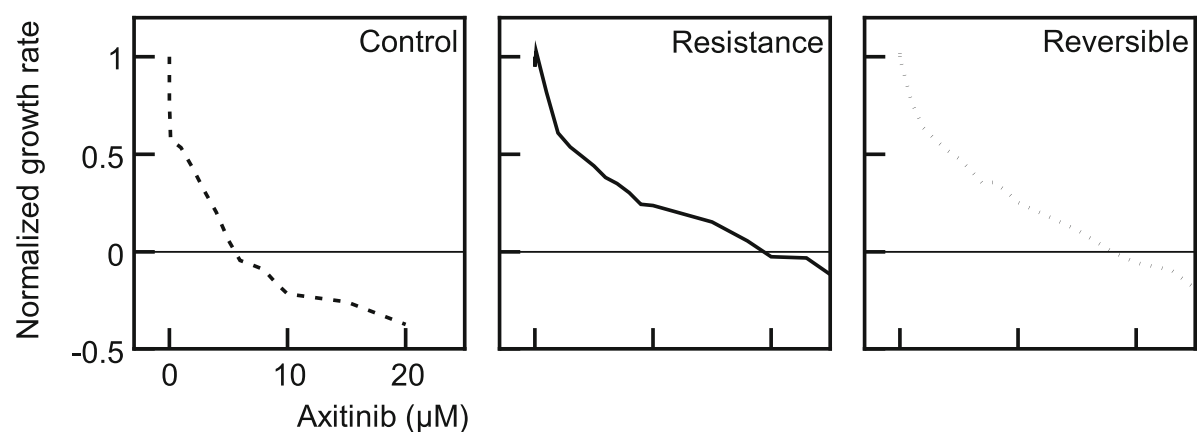

Fig. 7 Comparison of the IC, Gl, and GR parameters in evaluating anti-cancer drug resistance. The graph shown in the second column of Fig. 8A were analyzed in three respects. The same analyses were conducted for the $I C_{50},\left.G\right|_{100}$, and $G R_{100}$. The number of cells corresponding to the $I C_{50}$ in $(\mathbf{A}), G_{100}$ in (B), and $G R_{100}$ in $(\mathbf{C})$ is indicated by a horizontal line. Data from the control groups not exposed to drugs are shown in the left column, the resistant groups exposed to sunitinib are shown in the middle column, and the resistance reversible groups are shown in the right column

decreased by 1.43 (100\%) from the normalized growth rate of 1 , but this reduction was only 1.23 (86\%) for sunitinib-resistant cells. That is, a cross-resistance to everolimus existed in sunitinib-resistant SNU-228 cells. An explanation for this is that a complete inhibition of the proliferation of sunitinib-resistant cells indicated no cross-resistance to everolimus (0.91-fold, Table 3), but the higher concentrations of this drug produced a crossresistance to cell death (86\% compared to the control, Table 5). These patterns can vary from person to person, resulting in different conclusions in different cell types.
In SNU-267 cells, the GR $_{100}$ (efficiency) of everolimus increased by 1.35 -fold and the cell death at the high concentration decreased by $92 \%$ (Tables 4 and 5 ). Resistance (or cross-resistance) can be assessed in this way for all of the drugs used in this study.

\section{Comparison with existing studies}

Prior to this study, two reports had also established sunitinib-resistant cells using renal cell carcinoma cell lines and verified their cross-resistance. The major differences of those prior reports from this present 


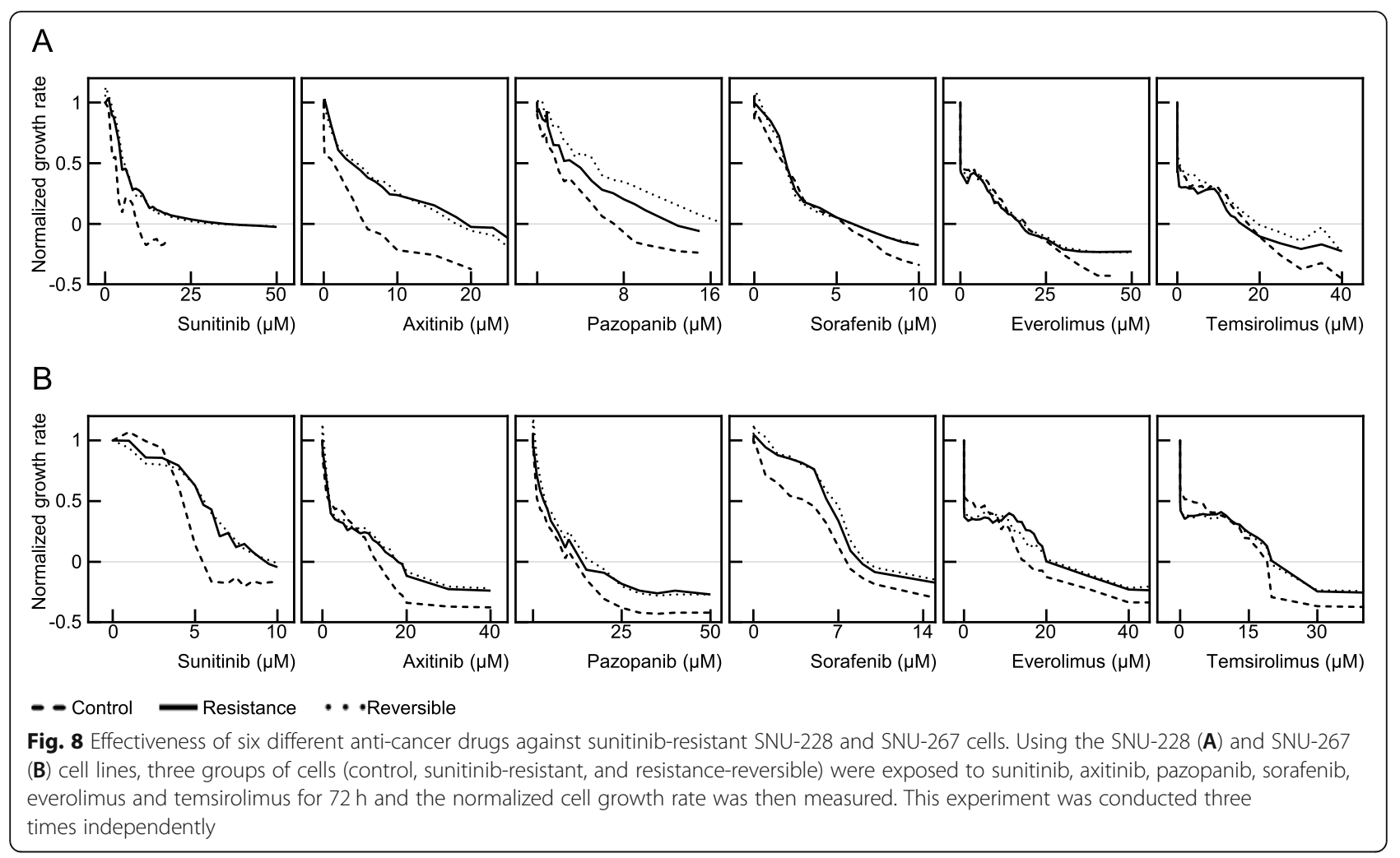

study were that the cells had been continuously to sunitinib, and the resistance indicator $\left(\mathrm{IC}_{50}\right)$ was not tracked over time but only compared at the beginning and end of the experiment. As mentioned earlier, it is recommended that information on drug resistance be viewed from a large framework, taking into account both the efficiency $\left(\mathrm{GR}_{100}\right)$ of these agents and their relative efficacy (Table 6).

\section{Discussion}

The tumor size (or volume) is an absolute criterion for determining cancer progression or the effectiveness of anti-cancer drugs, and tumor estimation technology is

Table 3 Comparison of resistance indicator candidates for six anticancer drugs in SNU-228 cells

\begin{tabular}{llllllll}
\hline & & Sunitinib & Axitinib & Pazopanib & Sorafenib & Everolimus & Temsirolimus \\
\hline IC50 & Control & 10.2 & $>20$ & 7.02 & $>10$ & 19.45 & 19.72 \\
& Resistant cells & $11.76(1.15)$ & $6.33(<0.32)$ & $9.22(1.31)$ & $2.38(<0.24)$ & $11.03(0.57)$ & $12.21(0.62)$ \\
& Reversible & $10.04(0.98)$ & $15.67(<0.78)$ & $9.62(1.37)$ & $2.95(<0.30)$ & $9.3(0.48)$ & $10.63(0.54)$ \\
Gl50 & Control & 2.88 & 1.74 & 1.57 & 1.8 & 0.08 & 0.01 \\
& Resistant cells & $4.65(1.61)$ & $3.31(1.90)$ & $3.54(2.25)$ & $1.86(1.03)$ & $0.001(0.01)$ & $0.003(0.30)$ \\
& Reversible & $5.08(1.76)$ & $3.77(2.17)$ & $5(3.18)$ & $1.83(1.02)$ & $0.0006(0.01)$ & $0.73(73.0)$ \\
GR50 & Control & 2.84 & 1.33 & 1.78 & 1.77 & 0.07 & 0.09 \\
& Resistant cells & $4.77(1.68)$ & $3.78(2.84)$ & $3.4(1.91)$ & $1.93(1.09)$ & $0.003(0.04)$ & $0.02(0.22)$ \\
& Reversible & $5.63(1.98)$ & $4.54(3.41)$ & $5.32(2.99)$ & $1.86(1.05)$ & $0.007(0.10)$ & $0.51(5.67)$ \\
G1100 & Control & 9.48 & 5.51 & 6.89 & 5.41 & 18.96 & 16.72 \\
& Resistant cells & $35.1(3.70)$ & $23.19(4.21)$ & $11.94(1.73)$ & $6.59(1.22)$ & $16.59(0.88)$ & $14.61(0.87)$ \\
& Reversible & $25.24(2.66)$ & $17.38(3.15)$ & $16.26(2.36)$ & $6.17(1.14)$ & $17.42(0.92)$ & $14.05(0.84)$ \\
GR100 & Control & 9.5 & 5.58 & 7.07 & 5.46 & 19.17 & 17.19 \\
& Resistant cells & $30(3.16)$ & $19.37(3.47)$ & $12.62(1.79)$ & $5.99(1.10)$ & $17.4(0.91)$ & $15.64(0.91)$ \\
& Reversible & $32.19(3.39)$ & $17.91(3.21)$ & $17.34(2.45)$ & $5.94(1.09)$ & $17.96(0.94)$ & $19.51(1.13)$ \\
\hline
\end{tabular}


Table 4 Comparison of resistance indicator candidates for six anticancer drugs in SNU-267 cells

\begin{tabular}{|c|c|c|c|c|c|c|c|}
\hline & & Sunitinib & Axitinib & Pazopanib & Sorafenib & Everolimus & Temsirolimus \\
\hline \multirow[t]{3}{*}{ IC50 } & Control & 5.66 & 7.49 & 4.91 & 6.46 & 8.22 & 11.64 \\
\hline & Resistant cells & $5.48(0.97)$ & $1.5(0.20)$ & $3.75(0.76)$ & $6.34(0.98)$ & $0.008(<0.01)$ & $0.008(<0.01)$ \\
\hline & Reversible & $5.61(0.99)$ & $1.93(0.26)$ & $3.51(0.71)$ & $6.71(1.04)$ & $0.33(0.04)$ & $0.01(<0.01)$ \\
\hline \multirow[t]{3}{*}{ Gl50 } & Control & 4.28 & 0.92 & 0.97 & 3.19 & 0.06 & 0.07 \\
\hline & Resistant cells & $5.1(1.19)$ & $1.14(1.24)$ & $1.92(1.98)$ & $5.59(1.75)$ & $0.007(0.12)$ & $0.006(0.09)$ \\
\hline & Reversible & $5.08(1.19)$ & $1.7(1.85)$ & $2.65(2.73)$ & $5.97(1.87)$ & $0.009(0.15)$ & $0.008(0.11)$ \\
\hline \multirow[t]{3}{*}{ GR50 } & Control & 4.27 & 1.68 & 1.28 & 4.25 & 0.86 & 2.58 \\
\hline & Resistant cells & $5.41(1.27)$ & $1.62(0.96)$ & 3.06 (2.39) & $6.11(1.44)$ & $0.009(0.01)$ & $0.01(<0.01)$ \\
\hline & Reversible & $5.57(1.30)$ & $1.72(1.02)$ & $3.46(2.70)$ & $6.7(1.58)$ & $0.009(0.01)$ & $0.0103(<0.01)$ \\
\hline \multirow[t]{3}{*}{ Gl100 } & Control & 5.45 & 13.15 & 9.45 & 7.67 & 15.02 & 18.92 \\
\hline & Resistant cells & $9.12(1.67)$ & $17.9(1.36)$ & $13.85(1.47)$ & $8.71(1.14)$ & $20.2(1.34)$ & $20.6(1.09)$ \\
\hline & Reversible & $9.75(1.79)$ & 16.85 (1.28) & 17.75 (1.88) & $9.43(1.23)$ & 22.05 (1.47) & $19.9(1.05)$ \\
\hline \multirow[t]{3}{*}{ GR100 } & Control & 5.46 & 12.96 & 11.81 & 7.67 & 15.01 & 19.02 \\
\hline & Resistant cells & 9.29 (1.70) & $18.08(1.40)$ & $13.67(1.16)$ & $8.82(1.15)$ & 20.29 (1.35) & $20.28(1.07)$ \\
\hline & Reversible & $9.73(1.78)$ & $18.11(1.40)$ & $16.46(1.39)$ & $9.37(1.22)$ & $21.81(1.45)$ & $19.85(1.04)$ \\
\hline
\end{tabular}

also evolving continuously $[12,13]$. This is not only the case in humans, but also in the safer experimental mouse models [14]. In these in vivo animal studies, whether the tumor size is smaller after treatment is the key measure of treatment effectiveness. Notably in this regard, in vitro cell line studies conducted prior to in vivo studies in animals have traditionally utilised the $\mathrm{IC}_{50}$, an indicator that does not take into account the number of cells before treatment [3]. Hence, the utility of $\mathrm{IC}_{50}$, the GIs (50 and 100), and the GRs (50 and 100), which are all candidates for the evaluation of chemotherapy effects, was compared in this present study.

In the current analyses, trends in drug resistance assessment indicators were observed in the process of resistance development in two RCC cell lines over 900 days of sunitinib treatment. The $\mathrm{IC}_{50}$ and $\mathrm{GI}_{50}$ were found not to reflect the occurrence of resistance over time. Although the $\mathrm{IC}_{50}$ and $\mathrm{GI}_{50}$ values were sometimes higher in sunitinib-treated cells than in control cells, it is concluded that these indicators could not stably represent resistance during the whole study period. The most recently developed indicator of anti-cancer drug effectiveness, the $G_{50}$, was found to reflect, statistically significantly, the process of establishing drug resistance in the RCC cells. The $\mathrm{GI}_{100}$ and $\mathrm{GR}_{100}$, indicators that include clinical goals, also reliably represented the process of establishing resistance. $\mathrm{GR}_{100}$, an indicator that takes the doubling time of the cells into account, is preferred to $\mathrm{GI}_{100}$, but both of these values indicate the efficiency of anticancer drugs. In addition, when considering the maximum amount of cell death as the indicator of the overall efficacy of anti-cancer drugs, suitable systems can now be established using these parameters to assess the resistance to anti-cancer drugs.

The $\mathrm{IC}_{50}$, an indicator of the cytotoxicity of anticancer drugs in vitro, has now been in use for a very long time. The shortcomings of this measure have now become apparent however through the experience of researchers and continued efforts have been made to improve it. In the evaluation of drugs other than anticancer agents, there are also reports that $\mathrm{IC}_{50}$ values are not stable either and can be applied only in limited cases [15]. Some prior reports have indicated that there is a problem with the MTT experimental method for calculating the $\mathrm{IC}_{50}$,

Table 5 Normalized growth rate reduction of SNU-228 and SNU-267 cells at the highest concentrations used of the indicated anticancer drugs

\begin{tabular}{llllllll}
\hline & & Sunitinib & Axitinib & Pazopanib & Sorafenib & Everolimus & Temsirolimus \\
\hline SNU-228 & Control & 1.13 & 1.37 & 1.24 & 1.34 & 1.43 & 1.45 \\
& Resistant cells & $0.93(0.82)$ & $1.02(0.74)$ & $1.06(0.85)$ & $1.18(0.88)$ & $1.23(0.86)$ & $1.23(0.85)$ \\
& Reversible & $0.94(0.83)$ & $1.06(0.77)$ & $0.93(0.75)$ & $1.17(0.87)$ & $1.24(0.87)$ & $1.24(0.86)$ \\
SNU-267 & Control & 1.17 & 1.38 & 1.42 & 1.36 & 1.33 & 1.35 \\
& Resistant cells & $1.05(0.90)$ & $1.24(0.90)$ & $1.27(0.89)$ & $1.24(0.91)$ & $1.23(0.92)$ & $1.24(0.92)$ \\
& Reversible & $1.01(0.86)$ & $1.22(0.88)$ & $1.27(0.89)$ & $1.23(0.90)$ & $1.19(0.89)$ & $1.23(0.91)$ \\
\hline
\end{tabular}


Table 6 Comparison between the current study findings and the results of prior studies of sunitinib resistance and cross resistance

\begin{tabular}{|c|c|c|c|c|c|c|}
\hline Publication year & $2013[2]$ & 2015 [9] & \multicolumn{2}{|c|}{ This study } & \multicolumn{2}{|c|}{ This study } \\
\hline Cell line & $\mathrm{ACHN}$ & $786-0$ & \multicolumn{2}{|c|}{ SNU-228 } & \multicolumn{2}{|c|}{ SNU-267 } \\
\hline Age & 22 & 58 & \multicolumn{2}{|l|}{51} & \multicolumn{2}{|l|}{43} \\
\hline Sex & male & male & \multicolumn{2}{|l|}{ male } & \multicolumn{2}{|l|}{ male } \\
\hline Ethnicity & Caucasian & Caucasian & \multicolumn{2}{|l|}{ Korean } & \multicolumn{2}{|c|}{ Korean } \\
\hline Origin & metastasized tumor & primary tumor & \multicolumn{2}{|c|}{ primary tumor } & \multicolumn{2}{|c|}{ primary tumor } \\
\hline Cytology & adenocarcinoma & clear cell adenocarcinoma & \multicolumn{2}{|c|}{ clear cell adenocarcinoma } & \multicolumn{2}{|c|}{ clear cell adenocarcinoma } \\
\hline Drug exposure method & continuous & continuous & \multicolumn{2}{|l|}{ pulse } & \multicolumn{2}{|l|}{ pulse } \\
\hline Drug concentration & up to $10 \mu \mathrm{M}$ & $5 \mu \mathrm{M}$ & \multicolumn{2}{|l|}{$3 \mu \mathrm{M}$} & \multicolumn{2}{|c|}{5.5 to $7 \mu \mathrm{M}$} \\
\hline Resistance indicator & $\mathrm{IC}_{50}$ & $I C_{50}$ & $\mathrm{GR}_{100}$ & Efficacy & $\mathrm{GR}_{100}$ & Efficacy \\
\hline \multicolumn{7}{|l|}{ Fold increase } \\
\hline Sunitinib & 5 & 3.1 & 3.16 & 0.82 & 1.70 & 0.89 \\
\hline Axitinib & & & 3.47 & 0.74 & 1.40 & 0.89 \\
\hline Erlotinib & & 4.5 & & & & \\
\hline Lapatinib & & 1.4 & & & & \\
\hline Pazopanib & & 1.6 & 1.79 & 0.85 & 1.16 & 0.89 \\
\hline Sorafenib & 6 & 1.2 & 1.10 & 0.88 & 1.15 & 0.91 \\
\hline Everolimus & 1 & 23 & 0.91 & 0.86 & 1.35 & 0.92 \\
\hline Temsirolimus & 1 & & 0.91 & 0.84 & 1.07 & 0.91 \\
\hline
\end{tabular}

and tried to improve on this cell viability measurement method [16]. However, as highlighted several times in this current study, the $\mathrm{IC}_{50}$ is not now recommended for use in anti-cancer drug efficacy or resistance studies, as it lacks meaning in terms of the clinical effects of these agents. This problem also exists for the $\mathrm{GI}_{50}$. Even though this parameter takes into account the number of seeded cells, a reduction in the rate of proliferation by just $50 \%$ is not clinically meaningful. Hence, new parameters including the relative doubling capacity inhibition (RD) and total growth inhibition (TGI) were introduced in a prior study, which highlighted the problems with the $\mathrm{IC}_{50}$ and $\mathrm{GI}_{50}$ [17]. Another study introduced the $\mathrm{GR}_{50}$, which corrected for the doubling time of the cells [10].

This present study is meaningful in that it has verified recently developed anti-cancer drug effectiveness evaluation indicators and proposed pharmacologically valid and clinically effective drug efficacy evaluation methods. Recent studies have highlighted the need to design experiments in a way that better enables bench to bedside translation in a number of areas, including chemotherapeutics $[18,19]$. In vitro cell research into anti-cancer and other drugs must adopt criteria that have relevance to the real world clinical environment. The efforts undertaken in this present study and others will pave the way for cell research data to be generated in a way that has a meaningful connection to potential clinical applications.

\section{Conclusion}

It is recommended based on our current findings to use the $\mathrm{GR}_{100}$ to assess the efficiency of an anti-cancer drug and also the maximal cell death it causes at high concentrations as an efficacy evaluation. Importantly, both the pharmacological perspectives and clinical utility aspects of an anti-cancer drug can thereby be satisfied when assessing resistance. The effectiveness assessment of anti-cancer drugs is essentially a core component of an resistance assessment because resistance indicates a loss of drug potency. The methodologies proposed in this present study will help with future evaluations of the effectiveness, resistance, and cross-resistance of anticancer drugs using in vitro cell research systems.

\section{Abbreviations}

Gl: Growth inhibition; IC: Inhibitory concentration; GR: Normalized growth rate inhibition; $y_{0}$ : Number of seeded cells on the $y$-axis; RD: Relative doubling capacity inhibition; RCC: Renal cell carcinoma; TGI: Total growth inhibition

\section{Supplementary Information}

The online version contains supplementary material available at https://doi. org/10.1186/s12885-021-08784-7.

Additional file 1 : Supplementary Table 1. Sunitinib cell exposure conditions.

Acknowledgements Not applicable. 


\section{Authors' contributions}

H Y, conceptualization, funding acquisition, manuscript writing; D-J K, statistical analysis; $\mathrm{H}-\mathrm{Y} \mathrm{C}$, in vitro experiment; SM K, in vitro experiment, manuscript writing; MI R, data analysis; Y-H K, manuscript review and writing; SW K, conceptualization, data analysis, and manuscript writing; all authors reviewed and approved the manuscript.

\section{Funding}

This work was supported by the National Research Foundation of Korea (NRF) grants funded by the Korean government (MSIT) (No. 2017R1C1B5073963 and 2021R1F1A1063083).

\section{Availability of data and materials}

Not applicable.

\section{Declarations}

Ethics approval and consent to participate

Not applicable.

\section{Consent for publication}

Not applicable.

\section{Competing interests}

The authors declare no competing financial or other interests in relation to this study.

\section{Author details}

'Division of Nephrology, Department of Internal Medicine, GangNeung Asan Hospital, University of Ulsan College of Medicine, Gangneung, Republic of Korea. ${ }^{2}$ Drug Evaluation Department, National Institute of Food and Drug Safety Evaluation, Ministry of Food and Drug Safety, Osong, Cheongju, Republic of Korea. ${ }^{3}$ Department of Pharmacology, Catholic Kwandong University College of Medicine, Gangneung, Republic of Korea. ${ }^{4}$ Department of Pharmacology, Asan Medical Center, University of Ulsan College of Medicine, 88, Olympic-ro 43-gil, Songpa-gu, Seoul, Republic of Korea. ${ }^{5}$ Bio-Medical Institute of Technology, University of Ulsan, Seoul, Republic of Korea.

Received: 15 July 2021 Accepted: 15 September 2021 Published online: 25 September 2021

\section{References}

1. Davey RA, Longhurst TJ, Davey MW, Belov L, Harvie RM, Hancox D, et al. Drug resistance mechanisms and MRP expression in response to epirubicin treatment in a human leukaemia cell line. Leuk Res. 1995;19(4):275-82. https://doi.org/10.1016/0145-2126(94)00159-8.

2. Sakai I, Miyake H, Fujisawa M. Acquired resistance to sunitinib in human renal cell carcinoma cells is mediated by constitutive activation of signal transduction pathways associated with tumour cell proliferation. BJU Int 2013;112(2):E211-20. https://doi.org/10.1111/j.1464-410X.2012.11655.X.

3. McDermott M, Eustace AJ, Busschots S, Breen L, Crown J, Clynes M, et al. In vitro development of chemotherapy and targeted therapy drug-resistant Cancer cell lines: a practical guide with case studies. Front Oncol. 2014;4:40. https://doi.org/10.3389/fonc.2014.00040.

4. Abel EJ, Culp SH, Tannir NM, Tamboli P, Matin SF, Wood CG. Early primary tumor size reduction is an independent predictor of improved overall survival in metastatic renal cell carcinoma patients treated with sunitinib. Eur Urol. 2011;60(6):1273-9. https://doi.org/10.1016/j.eururo.2011.07.008.

5. Halvorsen TO, Herje M, Levin N, Bremnes RM, Brustugun OT, Flotten O, et al. Tumour size reduction after the first chemotherapy-course and outcomes of chemoradiotherapy in limited disease small-cell lung cancer. Lung Cancer. 2016;102:9-14. https://doi.org/10.1016/.lungcan.2016.10.003.

6. Team TACSmaec: Managing Cancer as a Chronic IIIness. In. Edited by Society AC. cancer.org; 2019.

7. Eisenhauer EA, Therasse P, Bogaerts J, Schwartz LH, Sargent D, Ford R, et al. New response evaluation criteria in solid tumours: revised RECIST guideline (version 1.1). Eur J Cancer. 2009;45(2):228-47. https://doi.org/10.1016/j.ejca.2 008.10.026.

8. Brooks EA, Galarza S, Gencoglu MF, Cornelison RC, Munson JM, Peyton SR. Applicability of drug response metrics for cancer studies using biomaterials.
Philos Trans R Soc Lond Ser B Biol Sci. 2019;374(1779):20180226. https://doi. org/10.1098/rstb.2018.0226.

9. Gotink KJ, Rovithi M, de Haas RR, Honeywell RJ, Dekker H, Poel D, et al. Cross-resistance to clinically used tyrosine kinase inhibitors sunitinib, sorafenib and pazopanib. Cell Oncol (Dordr). 2015;38(2):119-29. https://doi.org/10.1007/s13402-015-0218-8.

10. Hafner M, Niepel M, Chung M, Sorger PK. Growth rate inhibition metrics correct for confounders in measuring sensitivity to cancer drugs. Nat Methods. 2016;13(6):521-7. https://doi.org/10.1038/nmeth.3853.

11. Labs P: Sutent ${ }^{\ominus}$ (sunitinib malate) capsules in. Edited by Pfizer. FDA; 2006.

12. Aydin F, Dertsiz L, Budak ES, Yildiz A, Ozbilim G, Gungor F. Measurements of tumor size using $C T$ and PET compared to histopathological size in nonsmall cell lung cancer. Diagn Interv Radiol. 2013;19(4):271-8. https://doi. org/10.5152/dir.2013.053.

13. Kim HS, Lee KS, Ohno Y, van Beek EJ, Biederer J. PET/CT versus MRI for diagnosis, staging, and follow-up of lung cancer. J Magn Reson Imaging. 2015:42(2):247-60. https://doi.org/10.1002/jmri.24776.

14. Mokhtar M, Kondo K, Takizawa H, Ohtani T, Otsuka H, Kubo H, et al. Noninvasive monitoring of anticancer effects of cisplatin on lung cancer in an orthotopic SCID mouse model using [(1)(8)F] FDG PET-CT. Oncol Rep. 2014; 31(5):2007-14. https://doi.org/10.3892/or.2014.3056.

15. Kalliokoski T, Kramer C, Vulpetti A, Gedeck P. Comparability of mixed IC(5)(0) data - a statistical analysis. PLoS One. 2013;8(4):e61007. https://doi.org/10.13 71/journal.pone.0061007.

16. He Y, Zhu Q, Chen M, Huang Q, Wang W, Li Q, et al. The changing 50\% inhibitory concentration (IC50) of cisplatin: a pilot study on the artifacts of the MTT assay and the precise measurement of density-dependent chemoresistance in ovarian cancer. Oncotarget. 2016;7(43):70803-21. https://doi.org/10.18632/oncotarget.12223.

17. Fiorentino FP, Bagella L, Marchesi I. A new parameter of growth inhibition for cell proliferation assays. J Cell Physiol. 2018;233(5):4106-15. https://doi. org/10.1002/jcp.26208.

18. Goldblatt EM, Lee WH. From bench to bedside: the growing use of translational research in cancer medicine. Am J Transl Res. 2010;2(1):1-18.

19. Lieu CH, Tan AC, Leong S, Diamond JR, Eckhardt SG. From bench to bedside: lessons learned in translating preclinical studies in cancer drug development. J Natl Cancer Inst. 2013;105(19):1441-56. https://doi.org/10.1 093/jnci/djt209.

\section{Publisher's Note}

Springer Nature remains neutral with regard to jurisdictional claims in published maps and institutional affiliations.
Ready to submit your research? Choose BMC and benefit from:

- fast, convenient online submission

- thorough peer review by experienced researchers in your field

- rapid publication on acceptance

- support for research data, including large and complex data types

- gold Open Access which fosters wider collaboration and increased citations

- maximum visibility for your research: over $100 \mathrm{M}$ website views per year

At BMC, research is always in progress.

Learn more biomedcentral.com/submissions 